\title{
0 trailer de animação infanto-juvenil como gênero para um modelo didático no ensino de inglês
}

\section{Children's and youth animated movie trailer as a textual genre for a didactic model of English language teaching}

\author{
Natalia Molan Cruzado 1 \\ Rosana Ferrareto Lourenço Rodrigues 2 \\ Anise Abreu Gonçalves D'Orange Ferreira ${ }^{3}$
}

\begin{abstract}
Resumo
Com o avanço das Tecnologias Digitais da Informação e Comunicação (TDIC) e o uso das redes de compartilhamento de informações, muitos recursos digitais têm se tornado potenciais instrumentos educacionais. Na aula de línguas, abrem-se possibilidades múltiplas de utilização de textos multimodais em suporte digital em diferentes serviços, tais como páginas web, vídeos em streaming, podcasts, entre outros. Os trailers de filmes, por exemplo, antes restritos às telas dos cinemas e à televisão, propagaram-se pelos ambientes virtuais diversificados, como as redes sociais, comportando-se como uma forma de linguagem dentro de determinados gêneros. Dentro de uma abordagem dos Gêneros Textuais, este artigo tem por objetivo apresentar uma análise preliminar de trailers como gênero textual, especificamente de animações infanto-juvenis, realizada por meio do modelo de análise proposto por Bronckart (2008, 2012 [2007]) no quadro do Interacionismo Sociodiscursivo (ISD). Foram analisados os trailers "Divertida Mente" e "Ralph quebrando a Internet", em seu contexto físico e sociossubjetivo de produção, e na infraestrutura geral do texto, constituído por plano geral, tipos de discurso e sequências mobilizadas no texto. Os resultados dos dados de análise trazem elementos contextuais e textuais para a caracterização do gênero estudado à luz das categorias ISD e têm potencial uso na sequência didática para o ensino de inglês com base em gêneros de textos digitais multimodais.
\end{abstract}

Palavras-chave: Gêneros Digitais Multimodais. Ensino de Inglês. Interacionismo Sociodiscursivo.

\begin{abstract}
Digital Information and Communication Technologies (TDIC) and the information sharing networks have advanced and brought up the potential use of many digital resources as educational tools. In language class, there are multiple possibilities of using multimodal texts in digital support and in different services, such as web pages, streaming videos, podcasts, among others. Movie trailers, for example, previously restricted to cinema screens and television, have spread through diverse virtual environments, such as social networks, and behave as a form of language within certain genres. From a textual genre approach, this article aims to present a preliminary analysis of children's and youth animated movie trailers as a textual genre carried out through the analysis model proposed by Bronckart (2008, 2012 [2007]) within the framework of Socio-Discursive Interactionism (SDI). The trailers "Inside Out" and "Ralph breaks the Internet" were analyzed, in their physical and sociosubjective production context, and in the general infrastructure of the text, consisting of a general plan, types of discourse and sequences mobilized in the text. The data analysis results in contextual and textual elements for the characterization of the genre in the light of the SDI categories and has potential use for a didactic sequence for English language teaching based on multimodal digital text genres.
\end{abstract}

Keywords: Multimodal Digital Genres. English teaching. Sociodiscursive interactionism.

\footnotetext{
1 Mestra. Unesp - Universidade Estadual Paulista "Júlio de Mesquita", Araraquara/ SP, Brasil. Orcid: https://orcid.org/00000002-1513-7419 E-mail: natalia.molan@unesp.br.

2 Doutora. Instituto Federal de Educação, Ciência e Tecnologia de São Paulo, São João da Boa Vista/SP, Brasil. Orcid: https://orcid.org/0000-0003-0332-4548 E-mail: rosanaferrareto@ifsp.edu.br.

${ }^{3}$ Doutora. Unesp - Universidade Estadual Paulista "Júlio de Mesquita", Araraquara/SP, Brasil. Orcid: https://orcid.org/00000001-5755-1434 E-mail: anise.ferreira@unesp.br.
} 


\section{Introdução}

O agir do professor em sala de aula reflete a concepção que ele tem de língua e linguagem. Docentes apreensivos questionam-se constantemente sobre maneiras de melhorar a prática docente e sobre como harmonizar os objetivos educacionais. Uma forma de lidar com a inquietação profissional é buscar, frequentemente, novas fontes que auxiliem no processo de ensino e aprendizagem dentro do ambiente educacional, seja ele físico ou virtual.

Muitos correm atrás de receitas milagrosas para mudar a educação e vislumbram nas tecnologias contemporâneas uma proposta de educação inovadora, mesmo estando cientes de que as tecnologias que chegam às mãos de alunos e professores trazem desafios (MORAN, 2013). Para Kenski (2008), esse desafio na educação não só consiste em adaptar-se aos avanços das tecnologias, mas também em orientar o caminho de todos para o domínio e apropriação crítica desses novos meios.

A apropriação de vídeos como recurso educacional tem proporcionado aos professores ilustrar e mostrar temas complexos, apresentar cenários desconhecidos, motivar e sensibilizar os alunos, e contar uma história com som e imagem (MORAN, 2013). O uso de trailers de filmes na aula de língua estrangeira parece ser uma ferramenta igualmente útil, uma vez que apresenta ao aluno essa associação de sons, imagens e linguagem escrita, o que o caracteriza como um recurso multimodal.

A multimodalidade se refere às várias modalidades usadas para criar significado quando nos comunicamos, o que não só revela a riqueza dos textos, mas também demanda maior compreensão e aprendizado. Afinal, com tantos novos gêneros textuais orais e escritos nesse turbilhão de novas tecnologias, urge explorar de forma plena o escopo de variedades de expressão de linguagens. Tornase assim crucial integrar, de forma coerente, esses processos multimodais na aula de línguas.

A produção e adaptação de materiais didáticos é uma alternativa proposta pela Linguística Aplicada para melhorar o processo de ensino-aprendizagem de línguas estrangeiras. Desse modo, busca-se avaliar e verificar se a utilização desta proposta como material didático é válida e aplicável como recurso pedagógico no ensino de Inglês como Língua Estrangeira (LE), considerando-se que trailers são materiais autênticos de fácil acesso para os alunos, além de não serem uma forma exaustiva de apresentação. Sumiya (2017) objetivou estudar o ensino-aprendizagem do francês como língua estrangeira por meio da produção do gênero multimodal tutorial em vídeos, embasada no quadro teóricometodológico do ISD. Os resultados apresentados pela autora demonstraram que o estudo do gênero permitiu a aprendizagem dos alunos no que concerne a outros saberes, os quais não estavam previstos no estudo inicial. Ademais, por meio da pesquisa, comprovou-se que a sequência didática proposta pela pesquisadora permitiu o desenvolvimento de capacidades de linguagem nos participantes. 
Este artigo tem por objetivo apresentar uma análise preliminar do gênero textual trailer, especificamente categorizado pelas distribuidoras/produtoras como animações infanto-juvenis, realizada por meio do modelo de análise proposto por Bronckart (2008, 2012 [2007]) e o quadro do Interacionismo Sociodiscursivo (ISD). A nossa análise inicial será ancorada no contexto físico e sociossubjetivo de produção, e na infraestrutura geral do texto, constituído por plano geral, tipos de discurso e sequências mobilizadas no texto, à luz do ISD (BRONCKART, 2012 [2007]). Para alcançar os objetivos, neste artigo, apresentam-se os pressupostos teóricos que fundamentam a pesquisa, a saber: ISD, a noção de texto, a definição de Gêneros Textuais em suas relações com multimodalidade, tecnologia e o modelo didático. Destaca-se a metodologia, a partir da apresentação do corpus e das categorias dos procedimentos de análise, bem como a análise preliminar do corpus à luz do ISD; e, por fim, tecem-se algumas considerações avaliativas da análise e seus resultados.

\section{Fundamentação Teórica}

2.10 Interacionismo Sociodiscursivo 4

De acordo com Bronckart (2008, 2012 [2007]), o interacionismo sociodiscursivo (ISD) fundamenta-se nos elementos da Psicologia Sociocultural, visando à interpretação a) da atividade humana, b) da maneira pela qual os agentes participam na significação da ação e c) do conhecimento que é construído e transformado na ação.

Bronckart (2012 [2007]) afirma que a linguagem é o elemento central decisivo para o desenvolvimento humano. Para o autor, seus estudos visam a demonstrar que as práticas situadas de linguagem são os "instrumentos maiores do desenvolvimento humano, não somente sob o ângulo dos conhecimentos e dos saberes, mas, sobretudo, sob o das capacidades de agir da identidade das pessoas" (op.cit. p. 9).

No Brasil, de acordo com Machado e Guimarães (2009), o ISD teve uma aceitação muito rápida e ampla na Linguística Aplicada. As autoras explicitam que a difusão das ideias do ISD, na linguística brasileira, se deu sob a influência da produção dos Parâmetros Curriculares Nacionais (PCN) e, portanto, ao quadro geral de reformas educacionais, que buscavam um referencial teórico capaz de dar coerência ao ensino-aprendizagem de Língua Materna (LM), com uma junção coerente de pressupostos da psicologia e das teorias linguísticas.

\footnotetext{
${ }^{4}$ As considerações teóricas desta seção são frutos de uma pesquisa de Mestrado de Molan (2019).
} 
O ISD viabiliza instrumentos que possibilitam a análise da aprendizagem em sentido amplo no âmbito epistemológico (do saber), pois propõe um modelo de análise de textos com base no aperfeiçoamento de capacidades de linguagem, tanto para a produção quanto para interpretação de textos, algo que nos levará a compreender quais dessas capacidades podem ser produzidas ao longo de uma sequência didática.

O modelo completo de análise de textos, largamente utilizado em inúmeros trabalhos no ensino de línguas e, principalmente, na produção de textos (GUIMARÃES; MACHADO, 2007) abrange vários níveis: o do contexto de produção, o da infraestrutura textual, visando ao nível organizacional e incluindo tipos de discurso e sequências, e os mecanismos de textualização e enunciativos (BRONCKART, 2012 [2007]; MACHADO, 2004).

$\mathrm{Na}$ didática de línguas baseada no ISD, esses níveis se associam a capacidades de linguagem que, de acordo com Machado (2005), relacionam-se diretamente ao que o ISD denomina agir linguageiro, o qual, por sua vez, articula-se a um agir praxiológico. 0 desenvolvimento dessas capacidades de linguagem é primordial para o aprimoramento do modo de agir com a linguagem, de forma mais consciente e engajada. Entretanto, não é o objetivo principal discutir aqui o conceito de capacidades de linguagem, pois o nosso interesse restringe-se a analisar trailers de animações infanto-juvenis do ponto de vista da análise de gênero por meio do modelo proposto por Bronckart (2008, 2012 [2007]).

\subsection{Os gêneros textuais}

De acordo com Bronckart (2012 [2007]), entende-se por texto "qualquer produção de linguagem situada, oral ou escrita" (BRONCKART, 2012 [2007], p. 71, grifos do autor) como, por exemplo, qualquer diálogo, pedido de emprego ou artigo de jornal. Portanto, como afirma Bronckart (2012 [2007], p. 71),

a noção de texto designa toda unidade de produção de linguagem que veicula uma mensagem linguisticamente organizada e que tende a produzir um efeito de coerência sobre 0 destinatário. Consequentemente, essa unidade de produção de linguagem pode ser considerada como uma unidade comunicativa de nível superior.

Como corrobora Leal (2011), os textos são produzidos e articulados às necessidades, interesses e às condições de funcionamento das formações sociais humanas, ou seja, a gêneros de atividades, onde os textos são construídos. Bronckart (2012 [2007], p.138) afirma que o texto "é necessariamente construído com base no modelo de um gênero, isto é, ele pertence a um gênero". Desse modo, a diversidade do "modo de fazer textos" ou "espécies de texto" (BRONCKART, 2012 [2007]) acontece devido aos contextos sociais muito diferentes e evolutivos no decorrer da história, e pode ser relacionada 
ao surgimento de novas motivações sociais e ao aparecimento de novas circunstâncias de comunicação. Bronckart (2012 [2007], p. 137) afirma que:

\begin{abstract}
na escala sócio-histórica, os textos são produtos da atividade de linguagem em funcionamento permanente nas formações sociais: em função dos seus objetivos, interesses e questões específicas, essas formações elaboram diferentes espécies de textos, que apresentam características relativamente estáveis (justificando que sejam chamadas gêneros de texto ${ }^{5} \mathrm{e}$ que ficam disponíveis no intertexto como modelos indexados, para os contemporâneos e para as gerações posteriores.
\end{abstract}

É importante ressaltar que esses gêneros não são considerados estáticos, justamente por se adaptarem às situações comunicativas. Cristovão (2015, p. 37) afirma que essa plasticidade do gênero deve ser considerada pois "ao realizar uma ação de linguagem, o agente confronta suas próprias representações da situação vivida com as representações já cristalizadas por formações sociais outras". De acordo com Bronckart (2010), os critérios para se legitimar os gêneros são diversos, tais como o efeito comunicativo, o suporte utilizado, o conteúdo temático, o tamanho etc. Afinal, um conjunto de textos com características estáveis e outro com contornos mais imprecisos compõem a organização dos gêneros, ou seja, essa organização é composta por gêneros claramente definidos e gêneros em que as definições ainda são vagas e divergentes.

Leal (2011), que apoia também no ISD sua pesquisa sobre o gênero multimodal cartoon em língua portuguesa, explica essa visão a partir de três aspectos essenciais. 0 primeiro aspecto é que os gêneros estão relacionados com a diversidade das práticas sociais, ou seja, apresentam características sociocomunicativas variáveis de acordo com as necessidades comunicativas humanas. $O$ segundo ponto valida o primeiro e versa sobre o fato de o gênero acompanhar o curso das formações sociais. $O$ terceiro aspecto refere-se ao caso de os gêneros se apresentarem como modelos disponíveis no intertexto ou arquitexto ${ }^{6}$ para que possam ser adotados e adaptados na elaboração de um novo texto empírico. Ao propor o estudo da organização textual do gênero cartoon, Leal (2011) repensou o modelo de análise do ISD e, através de uma análise sistemática, constatou que o humor, o desenho gráfico e a opinião sobre temas da realidade interagem de forma responsável pela função social do cartoon.

Lousada (2010) assegura que, em Língua Estrangeira (LE), há a necessidade de que os alunos tenham contato com gêneros mais ou menos dominados em Língua Materna (LM), uma vez que os gêneros apresentam características similares, facilitando o aprendizado em Língua Estrangeira. Ao analisar a produção textual dos participantes da pesquisa sobre o gênero multimodal de tutoriais em vídeos em francês, Sumyia (2017) evidenciou que a produção do tutorial em vídeo, em língua francesa,

\footnotetext{
5 Grifos do autor

6 Bronckart (2005) substitui o termo "intertexto" pelo termo "arquitexto"
} 
não foi considerada tarefa fácil, apesar de terem uma boa compreensão oral da língua-alvo. Observouse, ainda, que as capacidades de linguagem que permeiam o gênero ensinado foram desenvolvidas de maneira significativa, podendo ser comprovado esse desenvolvimento através da comparação entre a produção inicial e a produção final dos participantes.

Buscando conhecer trabalhos correlatos sobre gêneros de vídeo no ensino de língua estrangeira e o uso de trailer em proposta pedagógica, realizamos uma busca no Portal Capes a partir da combinação entre as palavras-chaves: gênero digital, multimodalidade, vídeos, trailers, animação, ensino de línguas e sequência didática. Foram obtidos 18 trabalhos como resultados. Os trabalhos são artigos publicados entre de 2013 e 2020 e versam sobre: multimodalidade de gêneros digitais ressignificando o ler e escrever; análise dos gêneros multimodais memes e história em quadrinhos; uso de animação como objeto de aprendizagem; e uso de narrativas digitais para o desenvolvimento de habilidades do multiletramento. Alguns desses trabalhos propõem o uso desses gêneros em sequências didáticas. Nenhum dos artigos tem como abordagem teórica o ISD. E nenhum deles tem como o objeto de estudo os trailers. Mesmo sem uma revisão exaustiva da literatura, os resultados da busca sinalizam uma lacuna em se tratando de estudos do gênero trailer em propostas pedagógicas para o ensino de línguas à luz do ISD. Com o intuito de propor a utilização do trailer na aula de LE, nos dedicaremos a uma análise desse gênero à luz do ISD.

\section{Uma proposta de caracterização do gênero multimodal trailer}

\subsection{Em busca do gênero textual multimodal trailer}

A classificação de um gênero textual pode ser efêmera, uma vez que os critérios para definição são diversos, provocando a extinção de alguns gêneros no decorrer da história, ou, ainda, fazendo com que esses gêneros sofram alterações de acordo com as práticas sociais, originando novos gêneros (BRONCKART, 2012 [2007]). Nesse sentido, concordamos com Sumyia (2017) em relação ao surgimento dos gêneros digitais, que são influenciados diretamente pelos avanços tecnológicos e sua apropriação.

Por meio das tecnologias de informação e comunicação, reúnem-se simultaneamente múltiplas semioses de texto, som e imagem, com diversas possibilidades de significação (ROJO, 2012). A multimodalidade oferece essas possibilidades combinadas, na mesma situação comunicativa, para produzir mensagens significativas. Cada mídia comunica por meio de um ou mais sistemas de sinalização e cada sistema de sinalização (por exemplo, sinais escritos, sinais falados, sinais pictóricos) é interpretável devido a um processo de percepção específico (FORCEVILLE; URIOS-APARISI, 2009). 
O trailer, a nosso ver, mostra-nos essa dinamicidade, uma vez que parece ter surgido como uma adaptação do gênero propaganda, anteriormente impresso, e foi se modificando de acordo com o contexto tecnológico vigente. Acredita-se que o trailer seja propaganda, porque anuncia outro objetoalvo, é um objeto-meio. Como publicidade, envolve outras esferas de conhecimento, como a psicologia de consumo. Segundo Cavalcanti (2015, p. 24),

o trailer é um segmento híbrido e complexo que permeia o campo narrativo, artístico e publicitário. Trabalhar uma definição do mesmo não é, por si só, tarefa das mais fáceis. Entretanto, podemos notar que apesar de uma seara de tipos e retóricas, os trailers apresentam algumas características comuns e, com certeza, um objetivo de ser. Estes elementos podem favorecer um estudo dele enquanto gênero.

Como discurso publicitário, o trailer é produzido por "especialistas" e está inserido numa situação comunicativa que responde às demandas da sociedade de consumo. Se, por um lado, assume o discurso daquele que gera o produto, por outro, tenta atingir os desejos de consumo do público visado 7 . Por esse motivo, pode adotar um discurso formal ou informal, a depender do público que quer atingir. Enfim, a resposta que o trailer deseja não é um enunciado verbal, mas uma atitude que implica o consumo do filme pelo público-alvo.

Com o avanço e aumento do acesso às tecnologias contemporâneas e sua consequente massificação pelo uso das redes de compartilhamento de informações, os trailers, antes restritos às telas dos cinemas e televisão, propagaram-se em ambientes virtuais diversificados, como as redes sociais, e parecem ter adquirido, também, um caráter de entretenimento; de objeto de consumo intermediário visando a um objeto-fim, parece ser algo que passa a ser consumido por si mesmo. 0 trailer pode ser considerado um gênero, mas é necessário analisá-lo em relação ao uso das linguagens, como os tipos de sequências que podem constituir a organização textual e as relações entre as linguagens verbal e não-verbal presentes no texto.

\subsection{Gêneros textuais e a didática de línguas}

A linguagem tem papel essencial no que concerne ao desenvolvimento humano e é concretizada a partir de textos. Muitos são os estudos que têm a preocupação do agir por meio da linguagem e do desenvolvido humano, pautados em uma abordagem centrada nos gêneros textuais, tanto na didática de língua materna (SCHNEUWLY et al. 2013 [2004]; ABREU-TARDELLI, 2010; dentre outros), como na

\footnotetext{
${ }^{7} \mathrm{~A}$ publicidade infantil tem se debatido entre atender as demandas de dois destinatários, porque precisa atingir os desejos da criança sem perder de vista que o poder financeiro, em geral, pertence ao adulto, conforme estudos de Ramos, Panozzo e Lazaretti (2011).
}

LínguaTec, Instituto Federal de Educação, Ciência e Tecnologia do Rio Grande do Sul, Bento Gonçalves 
didática de línguas estrangeiras (LOUSADA, 2006, 2010; CRISTOVÃO, 2009, 2010, 2015; dentre outros) e, ainda, no que diz respeito à multimodalidade na didática de línguas (LEAL, 2011; FERREIRA, MELO, 2016; SUMYIA, 2017).

Schneuwly et al. (2013 [2004]) afirmam que os gêneros podem ser observados como instrumentos de ensino, dado que eles estão entre o agente e a situação na qual ele age, direcionando e regulando o seu comportamento. Por meio da transformação do instrumento, há, também, uma alteração de comportamento do sujeito na situação. Assim, para esses autores, além do gênero textual mediar uma atividade, ele também deve concretizá-la, auxiliando o desenvolvimento das diferentes habilidades de linguagem que são mobilizadas durante as interações, seja de forma oral ou escrita.

Leal (2011, p. 167) ressalta que, uma vez que as novas tecnologias e o advento da Internet permitiram a integração do visual na atividade comunicativa ${ }^{8}$, a imagem passou a ter grande importância, pois pode-se constatar "uma relação de paridade entre o verbal e o não verbal". Portanto, há necessidade de "estudos sobre esses novos gêneros que circulam na web e suas implicações no ensino de línguas, dado que estamos diariamente cercados por eles" (SUMIYA, 2017, p. 31).

Nesse sentido, os dados da pesquisa TIC Educação 2018, realizada pelo Comitê Gestor da Internet no Brasil (CGI.br) sobre o uso de recursos digitais da Internet, corroboram o uso das novas tecnologias e o acesso à Internet como práticas nas escolas. Setenta e seis por cento dos professores utilizam a Internet para desenvolver ou aprimorar seus conhecimentos sobre o uso de tecnologias nos processos de ensino e de aprendizagem. Alunos e professores usam vídeos e tutoriais on-line como recursos de aprendizagem. Entre professores, esse uso cresceu em 16\% entre 2015 e 2016; entre alunos, de 63\% em 2015 a 78\% em 2018. Nas áreas urbanas, 97\% dos alunos acessam a Internet de dispositivos móveis, entre os quais os telefones celulares são os mais utilizados; $54 \%$ do uso de celular em atividades na escola ocorre na esfera pública, em que $68 \%$ do uso é por alunos do Ensino Fundamental II e 81\%, por alunos do Ensino Médio. Entre alunos do Ensino Fundamental da Secretaria Municipal do Estado de São Paulo, 47\% "acham legal participar de projetos que envolvam informática e robótica"; e 58\% dizem que "fica mais fácil aprender quando o professor usa tecnologia, jogos, música e outros recursos". Fazer pesquisa escolar, fazer tarefas escolares, pesquisar assuntos apresentados por professores em sala de aula, realizar tarefas em grupos, estudar para testes, fazer projetos escolares, usar jogos educacionais, realizar apresentações para os colegas, conversar com professores, publicar trabalhos escolares e fazer cursos on-line são atividades de alunos de escolas públicas nas zonas

${ }^{8}$ No Brasil, a primeira infraestrutura de Internet ocorre em 1992; em 1995, há abertura comercial; em 2005, consolidam-se as redes de alta velocidade; em 2018, a rede acadêmica chega a 100 Gb/s. (https://www.rnp.br/sobre/nossa-historia). 
urbanas, usando os dispositivos eletrônicos, entre os quais o uso de dispositivos móveis perfaz quase metade da porcentagem entre os demais dispositivos.

Dessa forma, coloca-se em evidência a importância de se utilizar os gêneros textuais (digitais) como instrumentos de ensino, uma vez que são guiados pelo meio e necessidades de comunicação. Acredita-se que, por meio deles, seja possível instigar o desenvolvimento de capacidades de linguagem (DOLZ, PASQUIER, BRONCKART, 2017 [1993]), capacitando os alunos a utilizá-las e adequá-las às mais variadas situações de comunicação com que são confrontados.

Para que os gêneros textuais sejam trabalhados em sala de aula e auxiliem no desenvolvimento das capacidades de linguagem dos alunos, no quadro do ISD, propõe-se que as intervenções em sala sejam orientadas por dois dispositivos: o modelo didático e a sequência didática. 0 modelo ou a sequência, nessa abordagem, não significam uma prescrição a ser seguida mecanicamente pelo professor e, sim, um dispositivo visando a se tornar um instrumento de trabalho moldado por esquemas de utilização (RABARDEL 2002; FOLCHER; RABARDEL, 2004), em uma reinterpretação do conceito vigotskiano de instrumento (MACHADO, LOUSADA, 2010; SILVA, 2018).

$\mathrm{Na}$ seção a seguir, apresentaremos considerações sobre o modelo didático e tecnologia específica do trailer, sem nos aprofundarmos em sequência didática no atual momento da pesquisa.

\subsection{Modelo didático e Tecnologia}

$\mathrm{Na}$ era digital da aprendizagem colaborativa, o uso do modelo didático como recurso para as aulas de línguas, em que se inserem tecnologias da informação e comunicação, é um desafio aos docentes "mudar o eixo do ensinar e optar pelos caminhos que levem ao aprender" (BEHRENS, 2013, p. 79). Segundo a autora, no paradigma tradicional, a linguagem oral e a escrita são contempladas num processo de repetição que leva a decorar datas, números, fórmulas, enfim, dados que muitas vezes não têm significado para os alunos no processo de aprendizagem.

As tecnologias digitais da informação e comunicação (TDIC) têm alterado nossas formas de trabalhar, de se comunicar, de se relacionar e de aprender. Na educação, as TDIC têm sido incorporadas às práticas docentes para promover aprendizagens mais significativas, alinhando o processo de ensinoaprendizagem à realidade dos estudantes e despertando maior interesse e engajamento dos alunos em todas as etapas da Educação Básica (BRASIL, 2018).

Kenski (1998) alerta para o fato de que o estilo digital engendra o uso de novos equipamentos e recursos, mas também novos comportamentos de aprendizagem. Isso quer dizer que é importante considerar recursos informatizados disponíveis, mas que esses 
dependem de projetos educativos e modelos didáticos que levem à aprendizagem e que possibilitem o espírito crítico e de atividades criativas. 0 recurso, por si só, não garante a inovação, mas depende de um projeto bem arquitetado, alimentado pelos professores e alunos que são usuários. $O$ computador é a ferramenta auxiliar no processo de 'aprender a aprender' (BEHRENS, 2013, p. 106).

Nossa proposta é trazer como recurso educacional tecnológico para as aulas de inglês o gênero digital multimodal trailer, vinculado ao modelo didático (MD), a partir de uma análise textual sob as lentes do ISD. Schneuwly et al. (2013 [2004]) propuseram o modelo didático de gênero com a intenção de fazer uma sondagem das "dimensões ensináveis" (SCHNEUWLY et al. 2013 [2004], p. 151) de um texto que pertence a determinado gênero. 0 modelo didático possibilita uma visão dos "objetos potenciais para 0 ensino" (SCHNEUWLY et al. 2013 [2004], p. 152), ou seja, é a partir da criação de um MD que se estabelece "o que pode ser objeto de ensino-aprendizagem dentro de uma situação específica de comunicação" (CRISTOVÃO, 2010, p. 106). No entanto, para criar um MD, alguns aspectos das características do gênero do texto devem ser levados em consideração, como as práticas sociais de referência; os conhecimentos sobre o gênero existentes no plano linguístico e discursivo, assim como no plano psicológico e, por fim, os conhecimentos sobre as capacidades de linguagem dos aprendizes. Esses são os aspectos relacionados entre si que corroboram a definição dos objetivos de aprendizagem.

De acordo com SCHNEUWLY et al. 2013 [2004]), o MD é trabalhado por meio de atividades e exercícios detalhados e apresentados em uma sequência didática (SD), construída metodicamente para se trabalhar determinado gênero em sala de aula, com a finalidade de assistir o aluno a ter maior domínio de um gênero textual, dando-lhe oportunidade de "falar ou escrever de maneira mais adequada numa dada situação de comunicação" (SCHNEUWLY et al. 2013 [2004], p. 83).

Para elaborar o MD, os autores genebrinos ampararam-se em inúmeros estudos, dentre eles, os do ISD, proposto por Bronckart (2006, 2008, 2012 [2007]) e sua equipe, após um longo trabalho de observação e análise de textos pertencentes a variados gêneros. Com o modelo de análise textual do ISD, pode-se ter a possibilidade de se construir uma descrição das características contextuais, discursivas e linguísticas do gênero textual em questão. Construído o modelo, parte-se para 0 planejamento das SDs. Essas são planejadas por apresentação da situação de comunicação, produção inicial, conjuntos de módulos e produção final e têm a finalidade de proporcionar aos alunos "práticas de linguagem novas ou dificilmente domináveis" (SCHNEUWLY et al. 2013 [2004], p. 83).

Na pesquisa em andamento, após a elaboração do MD, será feito o planejamento de uma SD para proporcionar aos participantes tal prática de linguagem. A sequência didática será aplicada de maneira preliminar a um grupo de professores da rede pública de ensino, como um minicurso de 
formação, a fim de que possam utilizar essa sequência em sala de aula. Após a apresentação dos trailers, os participantes produzirão outros trailers, selecionando cenas de filmes e inserindo narrações oralizadas, a fim de que se possa trabalhar a multimodalidade dos textos e a oralidade da língua-alvo.

Com o intuito de analisar características do gênero trailer, traremos o modelo do ISD na análise de dois trailers: "Divertida Mente9" e "Ralph quebrando a Internet 10".

3.40 corpus, instrumentos e categorias de análise para gênero

O corpus de estudo é composto por dois trailers de filmes animados, "Divertida Mente" (Inside Out) e "Wifi Ralph: Quebrando a Internet" (Ralph breaks the Internet). Ambos os filmes foram lançados por Walt Disney Pictures e têm como público-alvo adolescentes.

O desenho animado "Divertida Mente" é um longa-metragem de animação dirigido e coescrito por Pete Docter, produzido pela Pixar Animation Studios e lançado pela Walt Disney Pictures. 0 trailer traz Riley Anderson, uma adolescente de 11 anos, e sua família, sofrendo para se adaptar à vida em uma nova cidade. Entretanto, os sentimentos que habitam a mente da menina tomam conta do trailer. Alegria, Tristeza, Nojo, Medo e Raiva, emoções personificadas, tentam ajudá-la a lidar com os acontecimentos cotidianos, com o objetivo de trazer equilibrio à vida de Riley.

"Wifi Ralph: Quebrando a Internet" é um filme de animação longa-metragem, produzido pela Walt Disney Animation Studios e lançado pela Walt Disney Pictures, dirigido por Rich Moore e Phil Johnston, lançado em 2019. Esse filme é a sequência de "Detona Ralph" (Wreck-it Ralph), lançado em 2012. 0 trailer traz Ralph levando Vanellope para o universo expansivo e desconhecido da Internet, apresentado como uma cidade altamente tecnológica e brilhante com diversos elementos do mundo virtual interagindo com Ralph e Vanellope.

A análise preliminar do gênero trailer foi baseada no modelo de análise do ISD. Trata-se de um modelo descendente que parte do contexto de produção e interacional mais amplo em direção aos elementos linguístico-discursivos particulares. Tal análise se orienta por um modelo composto por três níveis textuais, além do contexto de produção físico e sociossubjetivo: a infraestrutura geral do texto, os mecanismos de textualização e os mecanismos enunciativos (BRONCKART, 2007). Focalizaremos o contexto de produção e o primeiro nível de análise de texto neste artigo: a infraestrutura geral do texto em que são considerados o plano geral, tipos de discurso e as sequências mobilizadas no texto. 0 plano geral se refere à forma como os temas são dispostos no texto, isto é, a organização dos conteúdos

\footnotetext{
9 https://www.youtube.com/watch?v=yRUAzGQ3nSY

$10 \mathrm{https} / / / \mathrm{www}$. youtube.com/watch?v=_BcYBFC6zfY
} 
temáticos. Os tipos de discurso revelam como se combinam as formas linguísticas relativas ao mundo do narrar e do expor e à implicação ou não no ato de produção, gerando o narrar implicado, o narrar autônomo, o expor implicado e o expor autônomo, tornando possível identificar os tipos de discurso propriamente ditos: discurso interativo, discurso teórico, narrar interativo e narração. As sequências mobilizadas no texto fornecem a planificação textual ou organização sequencial dos conteúdos e podem ser classificadas em narrativa, descritiva, argumentativa, explicativa e dialogal.

O contexto de produção descrito por Bronckart (2012 [2007]) é um conjunto de parâmetros que podem influenciar a produção textual. Nesse contexto, há a possibilidade de representação da situação de ação de linguagem em três mundos: o mundo físico, que diz respeito ao espaço e ao tempo no qual o sujeito está inserido no momento de produção textual, dividido em quatro parâmetros: lugar de produção, isto é, o local físico em que o texto é produzido; momento de produção, que se refere ao período no qual o texto é produzido; emissor/produtor do texto e receptor do texto. O mundo social e o mundo subjetivo são implicações de uma interação comunicativa que resulta de uma produção de texto. Esse contexto sociossubjetivo também pode ser dividido em quatro pontos para análise: lugar social, que diz respeito ao modo de interação em que o texto é produzido; posição social do emissor, ou seja, o papel social em que o emissor está inserido no momento da interação e que dá ao emissor o estatuto de enunciador; posição social do receptor e objetivos, que podem ser encontrados de acordo com o efeito ou efeitos que 0 texto pode causar em um destinatário.

Por se tratar de um modelo descendente, após a análise do contexto de produção físico e sociossubjetivo, verifica-se como se realiza a organização do texto. No seu primeiro nível, a infraestrutura geral se refere ao nível global do texto, constituído por plano geral, tipos de discurso e sequências mobilizadas no texto. O plano geral explica a forma como os temas são dispostos do texto, isto é, a organização dos conteúdos temáticos.

Além disso, há outras duas categorias para subdividir o mundo do narrar e do expor: a implicação ou não no ato de produção. Dessa forma, temos o narrar implicado, narrar autônomo, expor implicado e expor autônomo. De acordo com Bronckart (2012 [2007], p. 155), "esses mundos, assim como as operações em que se baseiam não são, entretanto, identificáveis, senão a partir das formas linguísticas que os semiotizam, sendo eles, portanto, dependentes das formas linguísticas". Assim, identifica-se a implicação ou autonomia no ato da produção na observação da existência ou não de dêiticos temporais, espaciais e de pessoa. A partir da identificação das coordenadas gerais do mundo (expor/conjunção e narrar/disjunção) e relação com o ato de produção (implicação ou autonomia), torna-se possível identificar os tipos de discurso: discurso interativo, discurso teórico, narrar interativo e a narração. 
Baseado nos estudos de Adam (2011 [1992]), Bronckart (2012 [2007]) propôs também a noção de sequência, que são modos de planificação textual ou organização sequencial dos conteúdos e podem ser classificadas em narrativa, descritiva, argumentativa, explicativa e dialogal. Bronckart (2012 [2007], p. 219) afirma que

essas diferentes sequências podem ser combinadas em um texto, em várias modalidades (encaixamento hierárquico, mesclas, etc.), e é da diversidade das sequências e da diversidade de suas modalidades de articulação que ocorre a heterogeneidade composicional da maioria dos textos.

A sequência narrativa é composta pela intriga e, embora haja muitas histórias com personagens implicados em acontecimentos consecutivos, só pode ser considerada narrativa se transformações forem provocadas por uma tensão existente.

A sequência descritiva não precisa ter uma ordem linear e é composta por fases, assim como a sequência narrativa. No entanto, essas fases estão encadeadas de maneira hierárquica e comportam outras três: a ancoragem, em que o tema ou o título é assinalado; a aspectualização, em que são enumerados os temas; e o relacionamento, em que os elementos descritivos são assimilados.

A sequência argumentativa também é composta por fases. A primeira fase é de premissas, em que há uma constatação de partida. Em seguida, vem a fase dos argumentos, ou seja, elementos que levam a uma conclusão; e a terceira fase é a apresentação de contra-argumentos, isto é, há restrição estabelecida pelos componentes. Na quarta fase, temos a conclusão, em que se deve compreender os efeitos dos argumentos e contra-argumentos.

Para a sequência explicativa, Bronckart (2012 [2007], p. 228) retoma o raciocínio explicativo apresentado por Grize (1981)

em que em uma dada constatação ou fenômeno incontestável apresentam-se como incompleto e se é legitimado pelo agente a partir da explicitação de causas e ou razões dessa constatação fazendo que, no fim desse desenvolvimento, as constatações sejam reformuladas.

Sendo assim, a sequência explicativa é composta por quatro fases: fase de constatação inicial; fase de problematização; a fase de resolução e a fase de conclusão-avaliação.

Por fim, temos a sequência dialogal, que se caracteriza por "concretizar-se apenas nos segmentos interativos dialogados" (BRONCKART, 2012 [2007], p. 230). Os turnos de fala servem para estruturar os segmentos, podendo realizar-se como discursos interativos primários, em que os turnos de fala são executados na interação verbal pelos agentes-produtores, ou discursos interativos secundários, nos quais os turnos de fala são efetivados no discurso de personagens. Pode ser dividida em três fases: a fase de abertura, em que os personagens entram em contato; a fase transacional, na qual o tema é 
construído entre os personagens; e a fase do encerramento, quando a interação é finalizada. Essa sequência é importante para o nosso trabalho pois os trailers podem se organizar em sequências dialogais, assim como podem contar narrativas.

Finalizamos, assim, o primeiro nível do modelo de análise do ISD, que diz respeito ao nível organizacional de análise do texto. Existem outros níveis de análise, os quais correspondem aos mecanismos de textualização e os mecanismos enunciativos, mas que não serão analisados neste artigo.

Para anotação do corpus, fez-se, inicialmente, uma análise introspectiva da linguagem, à luz da teoria, que precede uma corroboração com o uso de ferramentas. Além disso, a transcrição dos diálogos existentes nos textos foi feita em uma planilha a fim de analisar a linguagem verbal. Os outros cenários presentes nos trailers poderão ser analisados pelo software livre ELAN ${ }^{11}$, por permitir a análise de elementos multimodais, que englobam a linguagem verbal e não-verbal. A próxima seção consiste em breve análise dos trailers.

\subsection{Análise dos trailers "Divertida Mente" e "Ralph quebrando a Internet"}

Para o ISD (BRONCKART, 2012 [2007]), o contexto de produção remete ao início da situação de ação da linguagem. $O$ interlocutor, o qual pode ser uma empresa ou produtor de filmes, apresenta um filme que será, em breve, lançado nos cinemas. Nos trailers selecionados, por exemplo, após a primeira instância de apresentação dos personagens, temos a apresentação da produtora do filme como emissor do vídeo.

Em relação ao receptor dos trailers "Divertida Mente" e "Ralph quebrando a Internet", pode-se inferir que os vídeos são destinados a pessoas variadas, como adolescentes e, até mesmo, famílias. Isso pode ser justificado pelo conteúdo temático dos trailers e pelo local em que são veiculados, além das telas do cinema, estão disponíveis na Internet, rede constituída por pessoas ou organizações interconectadas com o objetivo de compartilhar valores e interesses comuns (SANTIAGO et al, 2014).

\begin{tabular}{|l|l|}
\hline \multicolumn{1}{|c|}{ CONTEXTO FísICO } & \multicolumn{1}{|c|}{ CONTEXTO SOCIOSSUBJETIVO } \\
\hline Emissor: Uma empresa, diretor, produtor de filmes & $\begin{array}{l}\text { Enunciador: Pode ser um personagem ou um } \\
\text { narrador, que gostaria de contar uma história. }\end{array}$ \\
\hline Receptor: Telespectadores crianças, jovens ou adultos. & $\begin{array}{l}\text { Destinatário: Telespectadores crianças, jovens } \\
\text { ou adultos. }\end{array}$ \\
\hline
\end{tabular}

11 O nome é uma abreviação de "EUDICO" (European Distributed Corpora Project) Linguistic Annotator". Disponível em: $<$ <ttps://archive.mpi.nl/tla/elan>.

LínguaTec, Instituto Federal de Educação, Ciência e Tecnologia do Rio Grande do Sul, Bento Gonçalves 
Local físico: Salas de cinema, site de compartilhamento de vídeos e redes sociais.

Momento: Os trailers são produzidos após a produção dos filmes, mas são veiculados e apresentados ao público em momentos antecedentes aos lançamentos dos filmes.
Local social: Salas de cinema, site de compartilhamento de vídeos e redes sociais.

Objetivos: Ganhar visibilidade, anunciar o filme que será lançado e convencer o telespectador a assisti-lo.

Quadro 1 - Contexto de produção dos trailers

Fonte: Elaboração das autoras

Pensando no local social dos trailers, esses podem ser encontrados em variados meios de publicação, como as telas do Cinema e o site YouTube. Quanto aos objetivos do gênero, além de divulgar um novo produto que estará disponível ao consumidor em breve e ganhar visibilidade, podemos acrescentar a intenção de causar divertimento, sem esquecer que a diversão é um dos atrativos para convencer o espectador a assistir ao filme. Isso pode ser observado na seleção das cenas, que causam curiosidade e divertimento, por meio da multimodalidade. O objetivo de produção de um trailer, inicialmente, é comercial, pois se deseja atingir o receptor de forma que o pequeno filme suscite nele a vontade de ir ao cinema quando o filme longa-metragem for lançado. Portanto, o propósito comunicativo desse texto está associado a despertar, no espectador, a motivação de assistir a um filme. 0 Quadro 1 apresenta informações sobre o contexto de produção dos trailers.

A análise do nível organizacional dos textos, o plano geral dos conteúdos temáticos, os tipos de discurso e as sequências textuais é apresentada no Quadro 2.

\begin{tabular}{|c|c|c|}
\hline Plano Global dos conteúdos temáticos & Tipos de discurso & Tipos de Sequência \\
\hline $\begin{array}{l}\text { a. } \quad \text { Apresentação dos personagens; } \\
\text { b. } \quad \text { Apresentação do trailer; } \\
\text { c. } \quad \text { Provocação entre os personagens; } \\
\text { d. } \quad \text { Conflitos de intenções e interesses entre os } \\
\text { personagens; } \\
\text { e. } \quad \text { Créditos; } \\
\text { f. } \quad \text { Anúncio de estreia }\end{array}$ & $\begin{array}{l}\text { Discurso interativo } \\
\text { implicado); } \\
\text { Relato interativo (narrar } \\
\text { implicado). }\end{array}$ & $\begin{array}{l}\text { Sequência narrativa; } \\
\text { Sequência dialogal; } \\
\text { Sequência injuntiva. }\end{array}$ \\
\hline
\end{tabular}

Quadro 2 - Infraestrutura geral do texto dos trailers

Fonte: Elaboração das autoras

Em relação à organização do conteúdo temático presente nos trailers, observa-se que "Divertida Mente" traz a classificação indicativa como primeiro conteúdo temático apresentado na tela. A sentença "The following PREVIEW has been approved for ALL AUDIENCES by the Motion Pictures Association of America, INC." avisa que o filme foi avaliado pela associação comercial americana que representa cinco principais estúdios cinematográficos de Hollywood. No trailer do filme "Ralph quebrando a Internet", não houve a apresentação desse conteúdo temático inicial, embora os filmes tenham sido produzidos pelo mesmo estúdio. Observa-se, ainda, a apresentação dos personagens, apresentação do trailer, 
provocação entre os personagens, conflitos de intenções e interesses entre esses, os créditos de produção e 0 anúncio de estreia do filme.

Quanto às sequências mobilizadas, o trailer organiza-se em uma mescla entre as sequências. Como o processo de organização dos trailers consiste em selecionar e organizar os acontecimentos de modo a formar uma história, há intrigas e uma tensão que desencadeia uma ou várias transformações. Além disso, observa-se que os diálogos são estruturados em turnos de fala, diretamente atribuídos aos personagens postos em cena, e, por fim, há uma sequência sustentada por um objetivo próprio, em que o agente produtor visa a fazer agir o destinatário de um certo modo ou em uma determinada direção. Ao apresentar a data e o aviso de que o filme estará no cinema em breve ("June 19"; "This Thanksgiving..."; "Loading in the theatre..."), o agente produtor tem por objetivo fazer com que o destinatário volte ao cinema para a estreia. Portanto, pode-se dizer que a dimensão da organização sequencial do conteúdo temático é constituída por sequências narrativa, dialogal e, por fim, injuntiva.

Quanto ao mundo discursivo, há o tipo de discurso do expor implicado: pode-se dizer que eles estão ligados ao mundo ordinário (conjunto) e a implicação pode ser verificada através de dêiticos de pessoas e espaciais e o uso de verbos no presente do indicativo ( "Riley, is everything ok?..." ; "I don't wanna to put the foot down..." ; "I do not like this new attitude..."), no imperativo ("Tease the safety position!"; "Go to your room!") e no futuro ("l'll show you attitude.."). Entretanto, pode-se observar, também, o tipo de discurso do narrar implicado: a criação do mundo discursivo tem as coordenadas gerais disjuntas das coordenadas do mundo ordinário do agente-produtor e dos agentes ouvintes. Nesse quadro, a origem apresenta unidades linguísticas do segmento de texto que se referem diretamente ao agente-produtor ("From the minds behind UP, Toy Story 3 and Finding Nemo"; "A major emotion picture"). Assim, pode-se dizer que os trailers se organizam em discurso interativo, uma vez que articulam uma situação de ação de linguagem que implica dois ou mais personagens alternando tomadas de turno em um espaço-tempo comum. A continuação da conversa depende da criação de um mundo discursivo que é "outro" em relação ao mundo ordinário dos agentes, pois mobiliza um conteúdo temático delimitado, semiotizado no quadro das restrições sintáticas e semânticas da língua-alvo. Não há elementos de origem espaço-temporal entre a conversa dos agentes, dessa forma podemos sugerir que as coordenadas gerais desse mundo discursivo são conjuntas às do mundo dos personagens em cena na interação. Assim, o expor dialogado que se realiza nesse mundo conjunto caracteriza-se pela implicação dos parâmetros da interação verbal posta em cena. Nos trailers, essa interação é apresentada em forma de discurso direto (cada personagem emite a sua fala) e, nesse caso, unidades desse segmento referem- 
se diretamente aos personagens-agentes da interação ( $($... you... ) ou à situação temporal desses agentes (was). Além disso, há também a possibilidade de os trailers apresentarem segmentos do relato interativo.

\section{Considerações Finais}

Parece consenso entre professores pesquisadores que 0 uso de material autêntico digital em aulas de língua estrangeira motiva o aluno a aprender a língua e possibilita compreender valores e conceitos, bem como proporciona aos professores uma abordagem que combina o ensino de gênero textual e o uso de tecnologia em sala de aula.

A fim de corroborar discussões dos estudos acerca do ensino-aprendizagem de línguas com base em gêneros de textos multimodais emergentes na era digital, realizamos uma análise preliminar do gênero trailer. Essa análise abarcou parte do primeiro nível de análise textual elaborado por Bronckart (2012 [2007]): o contexto de produção e a infraestrutura geral do texto. A próxima etapa será analisar os mecanismos de textualização, nível enunciativo e nível semântico, frente à necessidade de continuidade de estudos nessa perspectiva para que se possa propor "uma real discussão sobre as categorias do ISD aplicadas aos textos multimodais" (SUMYIA, 2017, p. 142), uma vez que a utilização de um gênero textual multimodal para o ensino é algo relativamente novo (SUMYIA, 2017), e, segundo pesquisas realizadas em base de dados científicas, esse é um dos primeiros estudos sobre trailers.

Os dados obtidos dessa primeira análise trazem elementos para a caracterização do trailer à luz do ISD (BRONCKART, 2012 [2007]) e têm potencial uso para a criação de uma sequência didática, que é parte componente do modelo didático, utilizado para caracterização de um gênero textual.

\section{Referências}

ADAM, J.-M. Les textes types et prototypes. Paris: Armand Colin, 2011 [1992].

BEHRENS, J. M. Projetos de aprendizagem colaborativa num paradigma emergente. Em: Novas tecnologias e mediação pedagógica. José Manuel Moran, Marcos T. Masetto, Marilda Aparecida Behrens (Org). 21 ed. rev. e atual. Campinas, SP: Papirus, 2013. (Coleção Papirus Educação). p. 73-140.

BRASIL. Base Nacional Comum Curricular: Ensino Médio. Brasilia: MEC/Secretaria de Educação Básica, 2018.

BRONCKART, J. P. Les diferentes facetes de l'interactionnisme sócio-discursif. Cadeidoscópio, Unisinos, vol. 3, n.3, p. 149 - 159, set/dez, 2005.

Atividade de linguagem, textos e discursos: por um interacionismo sociodiscursivo.

2. ed. São Paulo: Educ, 2012 [2007]. 
. O agir nos discursos: das concepções teóricas às concepções dos trabalhadores.

Campinas: Mercado das Letras, 2008.

. Linguagem e efeitos desenvolvimentais da interpretação da atividade. Campinas:

Mercado de Letras, 2010.

CAVALCANTI, I. C. O anjo da anunciação: a definição do gênero trailer e sua reconfiguração comunicacional. Dissertação de Mestrado - UFPB, 2015.

CRISTOVÃO, V. L. L. O ensino de leitura em língua estrangeira. In: ANJOS-SANTOS, L. M., BEATOCANATO A. P. M., CAMARGO G. P. Q. Gêneros textuais no ensino aprendizagem e na formação do professor de línguas na perspectiva interacionista sociodiscursiva. 1ed. Campinas, SP: Mercado das Letras, 2015, p. 19 - 63.

. Sequências didáticas para o ensino de línguas. In: CRISTOVÃO, V. L. L; DIAS, R. (Org.) O livro didático de língua estrangeira: múltiplas perspectivas. Campinas, SP: Mercado de Letras, 2010.

A relação entre teoria e prática no desenvolvimento do professor. In: MAGALHÃES, M. C. C. A formação do professor como um profissional crítico: linguagem e reflexão. 2. ed. Campinas, São Paulo: Mercado de Letras, 2009, p. 179 - 198.

DOLZ, J., PASQUIER, A; BRONCKART, J-P. L'acquisition des discours: emergence d'une compétence ou apprentissage de capacités langagières diverses? Nonada: Letras em Revista, vol. 1, núm. 28, mayo, 2017 [1993], pp. 156-173

FERREIRA; MELO, G Análise de textos multimodais da Web e o ISD. DELTA [online]. 2016, vol.32, n.1, pp.1-21. Disponível em: <http://dx.doi.org/10.1590/0102-445056772752226428>. Acesso em: 19 set. 2020.

FORCEVILLE, C. J.; URIOS-APARISI, E. (eds.). Multimodal metaphor. Applications of cognitive linguistics. New York: Mouton de Gruyter, 2009.

FOLCHER V., RABARDEL P. Hommes-Artefacts- Activités: perspective instrumentale. In.: P. Falzon (Eds) $L$ 'ergonomie, PUF, 2004. p. 251-268. Disponível em: <http://dx.doi.org/10.3917/puf.falzo.2004.01.0251>. Acesso em: 19 set. 2020.

GRIZE, J.B. Pou aborder l'étude des structures du discours quotidien. Langage Française. Paris: Larousse, n.50, 1981.

GUIMARÃES, A.M.M.; MACHADO, A. R.; COUTINHO, A. (Orgs). O interacionismo sociodiscursivo: questões epistemológicas e metodológicas. Campinas: Mercado de Letras, 2007. p. 77-97.

KENSKI, V. M. Educação e tecnologias: o novo ritmo da informação. Campinas: Papirus, 2008. 
KENSKI, V. M. Novas tecnologias. O redimensionamento do espaço e do tempo e os impactos no trabalho docente. Revista Brasileira de Educação n. 7, Associação Nacional de Pós-graduação e Pesquisa em Educação, jan-abr. 1998.

LEAL, A. A. A organização textual do gênero Cartoon: Aspectos linguísticos e condicionamentos não linguísticos. Tese (Doutorado) - Universidade Nova de Lisboa, Lisboa, 2011.

LOUSADA, E. G. Entre o trabalho prescrito e realizado: um espaço para a emergência do trabalho real do professor. Tese (Doutorado) - Pontifícia Universidade Católica de São Paulo, São Paulo, 2006.

LOUSADA, E. G. Elaboração de material didático para o ensino de francês. In: DIONÍSIO, A. P.; MACHADO, A. R.; BEZERRA, M. A. Gêneros Textuais \& Ensino. 1ed. São Paulo: Parábola Editorial, 2010. p. 81-94.

MACHADO, A.R.; LOUSADA, E.G. Apropriação de gêneros pelo professor: em direção ao desenvolvimento pessoal e a evolução do métier. Linguagem em (Dis)curso, v. 10, n. 3, p. 619-633, set./dez. 2010. Disponível em: <https://www.scielo.br/pdf/ld/v10n3/09.pdf>. Acesso em: 19 set. 2020.

MACHADO, A. R. A perspectiva interacionista sociodiscursiva de Bronckart. In: MEURER, J.L., BONINI, A. MOTTA-ROTH, D (Orgs.). Gêneros: teoria, métodos e debates. São Paulo: Parábola, Editorial, 2005, p. 237-259.

. Para (re) pensar o ensino de gêneros. Calidoscópio, v.2, n.1, p. 17-28, 2004.

MACHADO, A.R., GUIMARÃES, A.M.M. O interacionismo sociodiscursivo no Brasil. In: MACHADO, A.R.,;ABREU-TARDELLI, L.S., CRISTOVÃO, V.L.L. (Orgs.). Linguagem e educação: o ensino e a aprendizagem de gêneros textuais. Campinas: Mercado das Letras. 2009. p. 17-42.

MASCANHI, I. W. Análise de sequências didáticas de gêneros direcionadas ao ensino-aprendizagem de língua materna no ensino fundamental: aportes do interacionismo sociodiscursivo. 2013. Dissertação (Mestrado em Linguística e Língua Portuguesa) - UNESP, Araraquara, 2013.

MOLAN CRUZADO, N. A tradução de legendas e suas contribuições no ensino-aprendizagem de leitura em Inglês como Língua Estrangeira. Dissertação de Mestrado - Universidade Estadual Paulista "Júlio de Mesquita Filho", Araraquara, 2019.

MORAN, J. M. Ensino e aprendizagem inovadores com apoio de tecnologias. In.: Novas tecnologias e mediação pedagógica. José Manuel Moran, Marcos T. Masetto, Marilda Aparecida Behrens (Org). 21 ed. rev. e atual. Campinas, SP: Papirus, 2013. (Coleção Papirus Educação). p. 11-72.

RABARDEL, P. Pierre Rabardel. people and technology: a cognitive approach to contemporary instruments. Université Paris 8, pp.188, 2002. Disponível em: <https://hal.archivesouvertes.fr/file/index/docid/1020705/filename/people_and_technology.pdf>. Acesso em: 19 set. 2020.

RAMOS, F. B.; PANOZZO, N. S.P.; LAZARETTI, M. Publicidade na revista Recreio: configuração do consumidor infantil. 2011. Revista Nonada. V. 1, n.16, 2011. 
ROJO, R.; MOURA, E. (Org.). Multiletramentos na escola. São Paulo: Parábola, 2012.

SANTIAGO, S. S., KRIEGER, M. G., ARAÚJO, J. O gênero tutorial e a terminologia das redes sociais. In: Filologia e língua portuguesa, Faculdade de filosofia, São Paulo, v. 16, n.2, p. 381 - 402, 2014. Disponível em: <http://www.revistas.usp.br/flp/issue/view/7282>. Acesso em: 19 set. 2020. ISSN: 2176 9419.SANTOS, C. M. N. Trailer: Cinema e publicidade no mesmo rolo. Dissertação. Mestrado em Comunicação Social. Universidade Federal Fluminense. Niterói, 2004.

SCHNEUWLY, B.; et al. Gêneros orais e escritos na escola. 3 ed. Campinas, SP: Mercado das Letras, 2013 [2004].

SILVA, Sandra F. Do modelo didático ao ensino-aprendizagem de um discurso: polidez em um debate público em francês. In LOUSADA; ROCHA (orgs) Gêneros Textuais no Ensino e na Aprendizagem das Línguas: Dos Estudos Teóricos às Práticas Didáticas. Curitiba: Appris, 2018.

SUMIYA, A. H. O gênero multimodal tutorial em vídeo e suas contribuições no ensino-aprendizagem de francês como língua estrangeira por adolescentes. 2017. 174 f. Dissertação (Mestrado) - Universidade de São Paulo, 2016.

TIC Educação 2018. NIC.BR (ed.) Pesquisa sobre o uso das tecnologias de informação e comunicação nas escolas brasileiras São Paulo: Comitê Gestor da Internet BR, 2019. Disponível em: <https://data.cetic.br/cetic/explore?idPesquisa=TIC_EDU>. Acesso em: 8 set. 2020.

Data de submissão: 21/09/2020. Data de aprovação: 23/10/2020. 